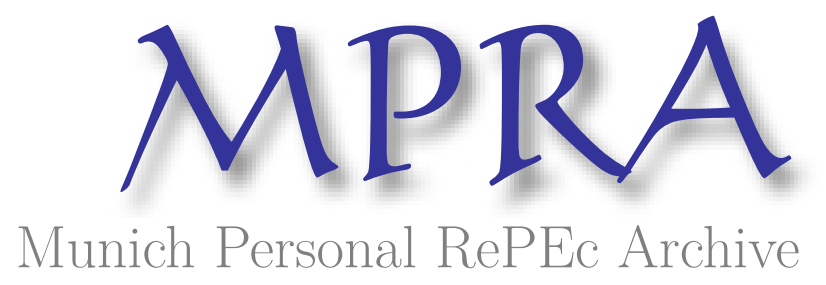

\title{
Estimating Labour and Output Gap: Evidence from the Athens Olympic Region in Greece
}

Belegri-Roboli, Athena and Michaelides, Panayotis G.

National Technical University of Athens

2005

Online at https://mpra.ub.uni-muenchen.de/74543/

MPRA Paper No. 74543, posted 17 Oct 2016 13:44 UTC 


\title{
Estimating Labour and Output Gap: Evidence from the Athens Olympic Region in Greece
}

\author{
ATHENA BELEGRI -ROBOLI and PANAYOTIS MICHAELIDES* \\ National Technical University of Athens, Faculty of Applied Mathematics and Physical \\ Sciences, Laboratory of Applied Economics, 9 Heroon Polytechneiou, Zografou \\ Campus, 157.80, Athens, Greece (*contact author, email: pmichael@central.ntua.gr)
}

\begin{abstract}
The present paper estimates potential labour and labour gap as well as potential output and output gap using a Cobb Douglas production function and a Hodrick-Prescott filter. We investigate the Athens Region in Greece by sector of economic activity, with the aid of the Non Accelerating Wage Inflation Rate of Unemployment (N.A.W.R.U.) concept. The results support the idea that the Athens region seems to be working, mostly, over the regional economy's capabilities, a fact which leads to inflationary pressure.
\end{abstract}

\section{Introduction}

The efforts being made to implement European Union (E.U.) policies and to deliver the Olympic Games of 2004 are said to have facilitated the creation of a new role for Athens, the capital of Greece, as a modern international and sustainable urban region (O.E.C .D., 2004). The purpose of the present paper is to assist decision makers to implement certain policies effectively. More precisely, a key question is related to the level of real labour and real output and their deviation from potential labour and potential output respectively, in the broader Athens Territory.

In recent years, economic policy has placed increasing emphasis on production gap even though it cannot be observed directly and its measurement is difficult (Slevin, 2001). When total labour and total output is well below the potential of the (regional) economy (so called potential labour and potential output, respectively, associated with a desirable level to be achieved) then a negative gap exists. In simple terms, current labour/production is below what the economy could normally sustain. In this situation there is spare labour/production capacity in the economy. The implication is that the rate of inflation is likely to fall because inflationary pressure is falling. When actual labour/production lies well above potential labour/production, there is a positive labour/production gap, meaning that inflation pressures will be rising. The labour gap is unlikely to persist over the long-run, as it is supposed that there will tend to be a wage and price adjustment process to restore equilibrium, where demand and supply are equal (Slevin, 2001). This often happens to a region at the end of a period of sustained economic growth, well above the longterm average growth of national output (Riley, 1999).

The Athens Region seems to fulfill this criterion for a number of reasons: (i) it captured benefits in the pre Olympic period, (ii) it enhanced its competitiveness and (iii) it is said to have improved its governance (O.E.C.D., 2004).

The paper is organized as follows: in Section II some stylized facts concerning the Athens Region are briefly presented; in Section III the methodological framework and the empirical results are discussed. Finally Section IV concludes the paper.

\section{The Athens Region: Some Stylized Facts}

Greece is the most easterly country within Western Europe. The area of greater Athens situated on the southern coast of mainland Greece is 3,200 square kilometers including the port of Piraeus. The Attica Regional Area - hereafter the Athens Region - 
concentrates roughly one third of the population of Greece on about $2.8 \%$ of the country's total area. More precisely, over the 1991-2001 period, the population of Greece increased by $6.8 \%$, to reach $10,940,000$ inhabitants, while the Athens (Metropolitan) Area grew also at $6.8 \%$, to $3,761,810$, inhabitants thus maintaining its share of about one third of the total Greek population and was mainly due to suburbanization driven by new infrastructure projects in outer areas confirming its dominant position as the main urban center of Greece.

However, the ageing trend in Greece, affecting strongly the Athens region, is more acute than in most other O.E.C.D. European countries. The number or pensioners is equivalent to $60 \%$ of the active population. Life expectancy is expected to rise by 4-5 years over the next decades, while female participation rates are projected to rise substantially. On the basis of demographic and labour force trends, it will reach twice the E.U. average by then, by far the highest in the OECD area (O.E.C.D., 2002).

Also, migration has played a decisive role in overall population growth during the past decade. The number of legally registered migrants, mainly from Albania, Bulgaria and other Eastern European countries, but also Pakistanis, Filipinos and Africans, in Greece is 797,091 with about the same number of unregistered immigrants. Almost half of them (376.732) live in the Athens Region representing $10 \%$ of the total population of the area, while the economic benefits from illegal migrant labour was estimated to about $1 \%$ of Greek G.D.P. ${ }^{1}$ (O.E.C.D., 2004). Migration impacts upon the local economy significantly because the informal economy accounts presently for $20-40 \%$ of the economic output of the Athens region, which is very high with social and economic costs and implications (O.E.C.D., 2004, Labour Institute, 2005).

Moreover, the Athens region contributed more than $38 \%$ to the Gross National Product (G.N.P.) of Greece (N.S.S.G., 2001). More precisely, the primary sector in the Athens Region accounted for $0.6 \%$ compared with the $8.2 \%$ for Greece as a whole; the secondary sector accounted for $18.3 \%$ versus $21.6 \%$ for Greece; and the tertiary sector accounted for $81.1 \%$ with $70.2 \%$ for Greece, as a whole. Consequently, the Athens region has a sectoral structure which corresponds to a relatively

\footnotetext{
${ }^{1}$ In the city of Athens is concentrated the largest number of immigrants $(140,626$ or $18.9 \%$ of population) which has been losing the population to the outer suburbs.
}

modern local economy (O.E.C.D., 2004). However, despite performing better than the rest of Greece in terms of Gross Domestic Product (G.D.P.), it falls behind the E.U. average since the per capita G.D.P. of the Athens region was 76.5 (EU15=100) (O.E.C.D., 2004). Also, labour market participation in the Athens region is low: The employment rate is $54.8 \%$, which is below both the Greek national average (57.8\%) and, of course, the European average $(73.8 \%)$. In addition, the proportion of the population under 15 years of age is less than the European average. Athens scores well in almost all "social" indicators, has a very low crime rate in Europe and a low income disparity. Business is mainly composed of small and medium size enterprises and the educational level of the Athenian labour force is high (O.E.C.D., 2004).

Since the late 90's, the Athens region was benefiting from a period of exceptional financing and worldwide promotion related to the Olympic Games of 2004 and the EU Community Support Funds (M.o.F., 2004), which had boosted investment in infrastructure facilities (i.e. hotel sector, sports facilities, etc) and a modern regionwide transport network. ${ }^{2}$ In terms of general economic development, Athens had been enjoying favourable macroeconomic conditions (high growth rates, greater stability in the Euro area, lower levels of inflation, etc).

At the same time, however, Athens faces complex inter-related problems. Its population is ageing; immigration is increasing in a previously homogenous society; parts of the urban area suffer from poor housing, environmental degradation and lack of green space, and the impacts of climate change are cause for concern; unemployment in the capital is high; imbalances in employment opportunities may well arise between the east and west of the region as well as among the different sectors, since new developments locate around the international airport, while old industrial sites in the west require redevelopment; investment finance may become scarce in the medium term as the EU Community Support Funds diminish and the investments connected with the Olympic Games are concluded. Moreover, the share of high productivity small and medium companies appears to be low; the economy faces a substantial debt burden; the trade deficit is sizeable; the size of the

\footnotetext{
2 This included a brand new international airport, urban highways and ring roads to decrease congestion, upgraded rail links, a new metro, a non-polluting bus fleet, and tramway lines which connect the city centre and the suburbs.
} 
unofficial economy is very big and competition from other European cities and economies is likely to intensify.

However, against this background, following O.E.C.D. (2004), Athens has considerable potential for growth in a number of areas. Specifically, it cites the health sector, including the fitness and health industry; the sports sector with hosting of major international events; education as an economic sector attracting foreign students which stimulates the housing and construction sectors as well as consumer products; the legal sector; the year-round conference industry; and new forms of tourism such as archaeological parks, eco-tourism, and high-quality cultural tourism.

All of these opportunities, however, require the Attica region to be well planned, accessible and socially agreeable. Like many metropolitan areas, Athens requires new institutional arrangements or reinforced co-operative arrangements in order to improve integration across administrative areas, between the policies and programmes of infrastructure agencies and service delivery, and between levels of government.

Athens needs clear strategic planning to take advantage of the opportunities that globalisation and eastward expansion of the European Union is bringing. In fact, Athens has considerable potential for development in its role as international gateway to Greece, the eastern part of the enlarged European Union and the Middle East. However, fulfilling this role will require strategic responses from the Greek government and the authorities of Athens and the surrounding region of Attica to a number of specific challenges (O.E.C.D., 2004). In particular, there is a need for developing a strategic vision for the region linking economic, social, and environmental planning. The government should monitor the impact of E.U. enlargement on the Greek and Athens economies, and develop a clear analysis of the best roles for Athens to play within Europe.

In this context, the present paper measures the labour and output gap in the Athens Region by sector of economic activity, in an attempt to assist decision makers to implement their policies effectively. It is obvious that a failure of the Athens region to address, for example, labour market problems would lead to additional strain upon the government and have broader economic and political implications for the country as a whole.

Thus, it is an important challenge for the economy's authorities to determine, as closely as possible, the level of potential output, the level of actual output at any given time, and the direction in which they are heading. As a result the authorities should place increased weight on a range of relevant indicators to assess the degree of pressure on the economy's production capacity.

It should be noted that, to date, there has been no specific study that has investigated relevant issues for the Athens region in Greece, by sector of economic activity. Only the studies by Apergis and Rezitis (2003), and Paraskevaides (1993), are partly related to our investigation, since they are dealing with the examination of Okun's law, and the stagflation conditions, respectively, that have hurt certain regional areas. Therefore, an investigation of the labour and output gap is of paramount importance for policy making in the Athens Region.

\section{Empirical Analysis}

\section{Methodological Framework}

Potential output may be described as a measure of aggregate supply of the regional economy. It represents the highest sustainable level of output that can be produced using available resources and technology. This implies optimal use of labour, capital and technology, without putting sustained upward pressure on inflation. The actual level of output produced in an economy is determined by the demand. The output gap is the difference between actual and potential output. The output gap is also referred to as spare capacity. The gap is positive when actual output exceeds the economy's potential and negative when actual output is below potential output. A positive gap is associated with excess demand in the economy, which may lead to inflationary pressures. On the other hand, when the gap is negative, this indicates that potential output exceeds demand. Potential output is often referred to as the output level consistent with stable inflation and full employment (Kenny, 1996). Consequently, potential output is usually associated with a desirable level of output.

Potential output is an unobservable variable and, thus, cannot be estimated directly. It can, however, be estimated with the aid of several statistical and theoretical methods. Statistical methods eliminate cyclical fluctuations from the actual output time series. The statistical methods include the time trend approach and the HodrickPrescott (HP) filter approach. To apply statistical methods, no other additional variables than actual output are needed. This is the reason why statistical 
methods are widespread (see, for instance, Claus, 2003).

On the other hand, statistical methods have several drawbacks, such as low estimation and forecasting efficiency, particularly when made over longer horizons (Stikuts, 2003). Also, the application of these methods requires relatively extensive time series. The most essential drawback of this approach, however, is that substantial changes in the economic structure due to which the level of potential output may change - and therefore be inconsistent with the forecast -, are not taken into account (Stikuts, 2003). This drawback is particularly noteworthy for the case of Athens, as with the advance of the European Market Integration in the 1990s and the preparation for the Olympic Games of 2004, a great number of changes in the economic structure took place.

Because of the several drawbacks of the statistical methods, the analysis based on the production function is used as an alternative method for measuring potential output. The most widely applied structural method is the estimation of the production function in the form of the CobbDouglas (CD) production function. Potential output thus estimated takes into account the changes in the economic structure.

General research on labour and output gap started with Okun (1962) and has been abundant ever since (for instance, see Kuttner, 1994). Roughly speaking, there exist two broadly used methods for the estimation of potential output: The HP-filter and the production function. For a review see Bolt and van Els (2000). For a brief presentation of some less popular techniques see Slevin (2001). The linear, two-sided HP-filter approach is a simple and widely used method by which the long-term trend of a (macroeconomic) series is obtained using only observable, i.e. actual, data. The trend is obtained by minimizing the fluctuations of the actual data around it, i.e. by minimizing the following function:

$\sum\left[\ln y(t)-\ln y^{*}(t)\right]^{2}-\lambda \sum\left[\left[\ln y^{*}(t-1)-\ln y^{*}(t)\right]-\left[\ln y^{*}(t)-\ln y^{*}(t-1)\right]\right]^{2}$

where $y^{*}$ is the long-term trend of the variable $y$ and the coefficient $\lambda$ determines the smoothness of the long-term (output) trend, expressing the potential output in this case.

The HP-filter approach has two positive features (Stikuts, 2002): First, the obtained trend is influenced by shocks. Second, it is simple to measure. However, the HP-filter alone produces a good result only when data on a relatively stable economic environment are used. In this case, the
HP-filter along with the relevant and econometric methods has to be used.

Numerous shocks affect economic growth in developing countries and regions, and substantial and accelerated changes in actual output do not necessarily signal either expansion or contraction of potential output. In this context, reliance on the HP-filter approach alone may lead to erroneous conclusions. In addition, sources often subject to criticism such as biases at the ends of the time series may influence the economic policymakers' decisions. Irrespective of the given drawbacks, the HP-filter approach is widely employed because of its simplicity.

This method, in contrast to the production function approach, does not use information provided by the factors of production, such as capital stock, workforce and technological development. It does not measure the influence of structural shocks on potential output and hence the output gap estimation may sometimes be biased. In order to avoid it, the estimation of the production function is used for the output gap estimation approach. $^{3}$ This method estimates a production function where real G.D.P. is some function of capital, labour and technology. Practically, its most important advantage lies in the possibility to account explicitly for different sources of growth (Billmeier, 2004). The production function is then estimated when the capital stock is being fully utilized and the labour force is fully employed.

This method has been used by various researchers (see Artus, 1977; Giorno et al., 1995; De Masi, 1997; Bolt and van Els, 2000; Senhadji, 2000; Slevin, 2001; etc.) Continuously, HP filter smoothing techniques have been used in the production function approach to filter technical progress and potential employment (Giorno et al., 1995; Bolt and van Els, 2000; Fagan et al., 2001).

The production function may take various forms, yet the most widely used is the CobbDouglas (CD) production function specification. ${ }^{4}$

\footnotetext{
${ }^{3}$ For overviews of the HP filtering method shortcomings see Harvey and Jaeger (1993), King and Rebelo (1993), Cogley and Nason (1995) and Billmeier (2004).

${ }^{4}$ The CD function has drawbacks as well (Stikuts, 2003): First, it is a simplified reflection of reality. For instance, it considers as homogenous the production and labour expanded originating from different sectors and skills. In other words, labour force or capital of the manufacturing industry is regarded as being the same as in the banking sector and can be easily transferred from one sector to another. Second, the data employed may result in a biased estimation, as in any econometric estimation, since the application of more accurate data is restricted by irregular availability (e.g. data concerning the utilisation of capital are not accessible with adequately
} 
The CD function may be written as follows (Stikuts, 2003; Billmeier, 2004):

$$
\mathrm{Y}_{t}=\mathrm{A}_{t} \mathrm{~L}_{t}{ }^{\alpha} \mathrm{K}_{t}{ }^{1-\alpha}(1)
$$

where $\mathrm{Y}_{t}$ denotes output at constant prices, $\mathrm{K}_{t}$ denotes capital stock at constant prices, $\mathrm{L}_{t}$ denotes the number of the employed persons, $\mathrm{A}_{t}$ characterizes the Total Factor Productivity (T.F.P.) and $\alpha$ is the elasticity of production factors.

After dividing by the number of employed persons and taking $\log s$ equation (1) yields a linearised form, which eliminates the possible multicolinearity problem of the explanatory variables and provides us with the estimate of the (1- $\alpha)$ coefficient using Ordinary Least Squares (O.L.S.):

$$
\ln \left(\frac{\mathrm{Y}_{t}}{\mathrm{~L}_{t}}\right)=\ln \mathrm{A}_{t}+(1-\alpha) \ln \left(\frac{\mathrm{K}_{t}}{\mathrm{~L}_{t}}\right)
$$

Potential output $\mathrm{Y}^{*}{ }_{t}$ is derived by inserting the potential values of the production factors. In other words:

$$
\mathrm{Y}^{*}{ }_{t}=\mathrm{A}^{*}{ }_{t} \mathrm{~L}^{*}{ }_{t}^{\alpha} \mathrm{K}^{*}{ }_{t}{ }^{1-\alpha}
$$

where $*$ denotes the potential value of the production factor.

The next step is to measure the potential value of production factors. The actual value of capital stock is used as a substitution for its potential value, as capital stock cannot fluctuate substantially, and it is assumed that the capital stock available is always used at its potential. Thus, we have that:

$$
\mathrm{K}_{t}^{*}=\mathrm{K}_{t}
$$

The Total Factor Productivity A* is partly estimated by the production function as the residual of equation (2), and the potential level is determined by the HP-filter to obtain a smooth time series. Consequently:

$$
\mathrm{A}^{*}{ }_{t}=\mathrm{A}_{\mathrm{s}_{t}}
$$

high frequency to be used in econometric studies). Third, natural or optimal factor utilisation capacity is difficult to define. Finally, the Solow residual is a substantial component of the production function, which is calculated as estimation residual and as such is economically unexplained and freely interpretable. Irrespective of its drawbacks, the CD function is one of the methods, which along HP-filter is widely used to estimate the potential output (Stikuts, 2003). For a brief review of the model's theoretical limitations see Thirlwall (2001, p. 185-7), which are, however, of limited practical character, as the author himself implies see (ibid , p. 187). where $A_{s_{t}}$ is the HP-filtered residuals time series of equation (2) characterising T.F.P.

Potential labour input is estimated using the NAWRU (non-accelerating wage-inflation rate of unemployment) concept. The NAWRU is the unemployment rate at which wage inflation is constant. Several studies show that the equilibrium unemployment rate changes over time, but it generally follows the actual unemployment rate (Layard et al., 1991).

Elmeskov's (1993), popular method is used in this paper to construct a time varying N.A.W.R.U. This approach has also been utilized by various researchers, for example see Bolt and van Els (2000), to estimate the output gap in European Union (E.U.) countries, and in Slevin (2001) for the case of Ireland. It is based on an equation, which relates the changes in unemployment with those in wage inflation:

$$
\mathrm{u}_{t}-\text { N.A.W.R. } \mathrm{U}_{t}=\lambda \Delta^{2} \mathrm{w}_{t}, \lambda<0
$$

where $u_{t}$ is the actual unemployment rate, N.A.W.R. $U_{t}$ is the (natural) unemployment rate, which has no effect on wage inflation and $\mathrm{w}_{t}$ is the average gross wage. $\Delta$ is the first difference, $\Delta^{2}$ is the second difference and $\Delta^{3}$ is the third difference operator.

Taking left and right first differences of equation (8) leads to an equation for $\lambda$ :

$$
\lambda=\frac{\Delta u_{t}}{\Delta^{3} w_{t}}, \Delta^{3} w_{t} \neq 0
$$

inserting the latter (9) into equation (8) we get:

$$
\text { N.A.W.R. } \mathrm{U}_{t}=\mathrm{u}_{t}-\frac{\Delta u_{t}}{\Delta^{3} w_{t}} \Delta^{2} w_{t}(8)
$$

Equation (10) implies that the N.A.W.R.U. is equal to the actual unemployment rate, which is adjusted by unemployment rate changes and wage inflation relationship. The resulting series is then smoothed to eliminate erratic movements using the HP filter. Consequently, potential employment is calculated as follows:

$$
\mathrm{L}_{t}^{*}=\mathrm{L}_{\mathrm{s}_{t}}\left[1-\mathrm{NAWRU}_{s t}\right](9)
$$

where $\mathrm{L}_{\mathrm{s} t}$ is the HP-filtered labour time series and N.A.W.R.U $s_{s}$ is the HP-filtered NAWRU time series.

Labour Gap is then calculated as follows:

$$
\mathrm{L}_{\text {gap }}=\left(\mathrm{L}_{t}-\mathrm{L}^{*}{ }_{t}\right) / \mathrm{L}^{*}{ }_{t}
$$


where $\mathrm{L}_{t}$ is the actual labour time series.

Substitution of the potential values of the production factors obtained from equations (4), (5), and (9) into equation (3) yields the time series of the potential output.

Output Gap is then calculated as follows:

$$
\mathrm{Q}_{\text {gap }}=\left(\mathrm{Q}_{t}-\mathrm{Q}^{*}{ }_{t}\right) / \mathrm{Q}^{*}{ }_{t}
$$

where $\mathrm{Q}_{t}$ is the actual output time series.

Finally, the productivity-of-labour (1) gap is calculated as follows:

$$
1_{\text {gap }}=\left[\left(\mathrm{Q}_{t} / \mathrm{L}_{t}\right)-\left(\mathrm{Q} *_{t} / \mathrm{L}^{*}{ }_{t}\right)\right] /\left(\mathrm{Q}^{*}{ }_{t} / \mathrm{L}^{*}{ }_{t}\right)
$$

\section{Data}

The regional data come from the National Accounts of the National Statistical Service of Greece, are on an annual basis and cover the period 1995-2001 when data are available, by sector of economic activity.

More precisely, the time series on actual labour comes from the National Accounts concerning the reported sixteen (16) sectors of economic activity, see Table 1.

\section{Table 1: Industry Classification}

\section{Please Insert Table 1}

Also, because the relevant data are not available, the wages by sector of economic activity in the Athens Region were calculated under the assumption that the sectoral wages at the national level are equal to the corresponding wages of the Athens Region. This assumption is supported by the fact that about $38 \%$ of the total number of employees in Greece work in Athens. Also, we have made the same assumption about the unemployment rate since no relevant data for each sector of economic activity in the Athens Region is available. Data on the capital stock at constant prices is not published. However, we estimated it using the popular Perpetual Inventory Method.

\section{Empirical Estimates and Discussion}

Figure 1 illustrates the labour gap, by sector of economic activity for each year.

Fig. 1: Labour Gap by sector of economic activity in the Athens Region (1995-2001)

\section{Please Insert Figure 1}

In the following table (Table 2) the labour gaps are presented in greater detail.

Table 2: Labour Gap by sector of economic activity in the Athens Region (1995-2001)

\section{Please Insert Table 2}

Figure 2 illustrates the output gap, by sector of economic activity for each year.

Fig. 2: Output Gap by sector of economic activity in the Athens Regional Department (1995-2001)

\section{Please Insert Figure 2}

In the following table (Table 3 ) the output gaps are presented in greater detail.

Table 3: Output Gap by sector of economic activity in the Athens Region (1995-2001)

\section{Please Insert Table 3}

Figure 3 illustrates the productivity-oflabour gap, by sector of economic activity for each year.

Fig. 3: Productivity-of-Labour Gap by sector of economic activity in the Athens Region (1995-2001)

\section{Please Insert Figure 3}

In the following table (Table 4) the productivity-oflabour gaps are presented in greater detail.

Table 3: Productivity-of-Labour Gap by sector of economic activity in the Athens Region (19952001)

\section{Please Insert Table 4}

The empirical results show that in the time period 1995-2001 the Athens Region seems to be operating, with very few exceptions, at levels which are higher than its capacity, especially as regards to employment. This also implies that the actual employment and output levels achieved are, mostly, higher than the ones that would not cause inflationary pressures.

Also, we observe that the largest labour gaps are to be found for sector 1 (agriculture, farming and forestry), sector 2 (fishing) and sector 3 (mining), i.e. the primary sector of production. 
This finding, i.e. the over-utilisation of labour, can be characterised as expected given the fact that this sector of economic activity is one in which, traditionally, the Athens area is not specializing.

Of course, this finding is also an expression of a very important structural problem of the Greek economy as a whole, especially when compared to other European countries. Finally, the rest of the sectors face a similar range of gaps, among them, indicating an almost similar and homogeneous diffusion of the gap in the regional economy.

Regarding the output gap, we observe that the Athens regional economy operates at levels which are higher than its capacity except for sectors 3 (mining) and 16 (private households with employed persons). Also, after 1998, as can be seen in Tables 2 and 3, potential labour and potential output tend to rise, a phenomenon which can also be characterised as expected, since the convergence plan of the Greek economy in the 1998-2001 time span has lead to a gradual decrease of N.A.W.R.U., which in turns had an increasing effect on potential labour and output, combined with the Olympic Games of 2004 preparation period (M.o.F., 1998).

Meanwhile, the N.A.W.R.U. in the Athens Region was higher than the actual rate of unemployment in the time period 1999-2001, a fact which implies that the inflationary pressures of the period are related, ceteris paribus, with the unemployment decline.

Finally, regarding the productivity-oflabour gap, we observe that for the great majority of economic sectors and years the real productivity of labour seems to be lower than its potential level, a fact which implies that given the number of the employed persons, the output produced per labourer is lower than its potential value.

This situation is partly due to the recent economic conjecture (Olympic Games, E.U. funding, etc) which enables the various economic sectors to continue to operate at low (labour) productivity levels. However, as soon as this situation ceases to exist the various sectors will not be able to operate at such low levels and their productive capacities, as well as their production technology, will have to be re-examined.

This result is consistent with the findings of Mora et al. (2005) that the (labour) productivity levels remain relatively low in economies with low levels of development among E.U. countries (Greece, Portugal, etc). It is also consistent with the findings of Bosworth and Kollintzas (2001) about the growth prospects of the Greek economy, that the longer-term task is fundamentally one of raising labour productivity.
If this situation is not reversed, then countries like Greece will find that their competitiveness is negatively affected. As a consequence, there will be growing pressure on countries with lower levels of productivity, which are losing economic activity and whose unemployment levels will inevitably rise. This fact, together with the low level of inter-European migration will have an adverse effect on the poorest countries and local economies like the Athens region (Mora et al., 2005), since regional productivity differences prove to be a main determinant behind observed welfare inequality in the European context (Ezcurra et al., 2005). In this case, the (stag)inflation - unemployment dilemma becomes relevant for the Athens economy.

\section{Concluding Remarks}

In the present paper we estimated potential labour and labour gap, by sector of economic activity, in the Athens Region with the aid of the NAWRU concept in an attempt to investigate whether the Athens economy is operating at levels over its capacity, which in turns could be blamed for inflationary pressures. The results show that most sectors do operate over the regional economy's capacity and are responsible for creating inflationary pressures.

It is well known, that in periods of expansion, the economy can function above the levels of the corresponding trend line (M.o.F., 1998), that is to say the real magnitudes are larger than the corresponding potential ones. The opposite happens in periods of recession. In this context, and given the expansion of the Athens economy, our findings can be regarded as expected.

Thus, we can suppose that, when the activities connected to the expansion of the economy are completed, and the employment level reaches its potential value, then the unemployment rate of the Athens region will probably increase.

This finding seems to be in accordance with the most recent evidence concerning the Greek economy as a whole. More precisely, the unemployment rate for year 2004 has increased significantly when compared to its prior values (B.o.G., 2005, p. 37) signifying the end of a long period of expansion lasting until 2004 related, obviously, with the Olympic Games in the Athens Region and the EU funding. (B.o.G., 2005, p. 26- 
28)..$^{5}$

Closing, we would like to stress the fact that all estimates of output gap are subject to a margin error and the production function estimate is obviously contingent on an estimate of the Capital Stock as well as of N.A.W.R.U. to calculate potential employment (Stikuts, 2003).

In other words, the methodology we used is popular and appropriate, but it should be treated with caution since, both the level of potential output and the output gap are estimated numbers, and therefore, there is some uncertainty in their calculation. For the case of the Athens Region, this uncertainty may grow larger now because the length of the data series sets a limitation, since no other sufficient and reliable data are available and so we are prevented from attaining a statistically excellent level of estimation.

In the words of Arthur Okun: "The quantification of potential output - and the accompanying measure of the 'gap' between actual and potential - is at best an uncertain estimate and not a firm, precise measure" (Okun, 1962, cited in Billmeier, 2004, p. 3).

Conclusively, we believe that future and more extended research on the subject would be of great interest, including the estimation of the labour and output gap for other crucial regions within the E.U. territory.

\section{Acknowledgements}

The authors would like to thank Mark Taylor, editor, an anonymous referee of this Journal, as well as Efthymios Tsionas for helpful comments on an earlier draft of this paper. Financial support from the European Social Fund and the Labour Institute of the General Confederation of Greek Labour Unions is greatly appreciated.

\section{References}

Apergis, N. and Rezitis, A. (2003) An Examination of Okun's law: evidence from regional areas in Greece, Applied Economics, 35, 1147-1151.

Artus, J.R. (1997) Measures of Potential Output in Manufacturing for Eight Industrial countries, 1955-78, Staff Papers, International Monetary Fund, Vol. 24, 1-35.

\footnotetext{
5 According to the recent findings of Christopoulos et al. (2005) regarding Greece and other EU countries, government size is an important determinant of the (un)employment rate.
}

Bank of Greece - [B.o.G.] (2005) Governor's Report-Annual Report for year 2004, Athens, p. 37 (in Greek).

Billmeier, A. (2004) Ghostbusting: Which Output Gap Measure Really Matters?, IMF Working Paper WP/04/146.

Bolt, W. and van Els, P. J. A. (2000) Output Gap and Inflation in the EU, De Nederlandsche Bank Staff Report No. 44.

Bosworth, B. and Kollintzas, T. (2001) Economic Growth in Greece: Past Performance and Future Prospects, in (Eds.) Bryant, R., Garganas, N. and Tavlas, G., Greece's Economic Performance and Prospects, Bank of Greece and The Brooking Institution, Athens, 189-237.

Christopoulos, D., Loizides, J. and Tsionas, E. (2005) Applied Economics, 37, 1193-1199.

Claus, I. (2003) Estimating Potential Output for New Zealand, Applied Economics, 35, 751-760.

Cogley, T. and Nason, J. (1995) Effects of the Hodrick - Prescott Filter on Trend and Difference Stationary Time Series: Implication for Business Cycle Research, Journal of Economic Dynamics and Control, Vol. 19, 253-278.

De Masi, P. (1997) I.M.F. Estimates of Potential Output: Theory and Practice, I.M.F. Working Paper 97/177.

Elmeskov, J. (1993) High and Persistent Unemployment: Assessment of the Problem and Its Causes, O.E.C.D. Economics Department Working Paper, No. 132.

Ezcurra, R., Gil, C. and Pascual, P. (2005) Applied Economics, 37, pp. 1423-1437.

Fagan, G., Henry, J. and Mestre, R. (2001) An Area - Wide Model (AWM) for the Euro Area: Estimates and assessment, ECB Working Paper No. 17.

Giorno, C., Richardson, P., Roseveare, D. and van der Noord, P. (1995) Estimating Potential Output, Output Gaps and Structural Budget Balances, O.E.C.D. Working Papers, No 152.

Harvey, A.C., and Jaeger, A. (1993) Detrending Stylized Facts and the Business Cycle, Journal of Applied Econometrics, Vol. 8, 231-247.

Kenny, G. (1996) Capacity Utilization in Irish Manufacturing, Central Bank of Ireland Technical Paper Series, No. 2/RT/96.

King, R.G. and Rebelo, S. (1993) Low Frequency Filtering and Real Business Cycles, Journal of Economic Dynamics and Control, Vol. 17, 361-368.

Kuttner, K. (1994) Estimating Potential Output as a Latent Variable, Journal of Economics and Business Statistics 12, 361-368. 
Labour Institute (2005) Migration Policy and Migrants' Rights, Athens, Greece (in Greek).

Layard, R., Nickell, S., Jackman, R. (1991)

Unemployment, Macroeconomic Performance and the Labour Market, Oxford University Press.

Ministry of Finance - [M.o.F.] (2004) Ergorama: The Integrated Information System, Athens (in Greek).

Ministry of Finance - [M.o.F.] (1998) Current Developments and Prospects of the Greek and International Economy, Athens (in Greek).

Mora, T., Lopez-Tamayo J. and Surinach, J. (2005) Applied Economics, 37, 2001-2008.

National Statistical Service of Greece [N.S.S.G.] (1991, 2001) Results of Census (http://www.statistics.gr).

O.E.C.D. (2002) OECD Economic Survey of Greece, Paris, France.

O.E.C.D. (2004) Territorial Reviews Athens - Greece, Paris, France.

Okun, A. (1962) Potential G.N.P.: Its Measurement and Significance, Proceedings of the Business and Economics Section, American Statistical Association, 98-104.

Paraskevaides, P. (1993) Income Inequalities and Regional Distribution of the Labour Force, Center of Planning and Economic Research, Athens.

Riley, G. (1999), Output Gap (http://dspace.dial.pipex.com/town/parade/rcb48/ou tput.htm).

Senhadji, A. (2000) Sources of Economic Growth: An Extensive Growth Accounting Exercise, I.M.F. Staff Paper Vol. 47, No. 1.

Slevin, G. (2001) Potential Output and the Output Gap in Ireland, Central Bank of Ireland Technical Paper, 5/RT/01, September 2001.

Stikuts, D. (2003) Measuring output gap in Latvia, Latvijas Banka, Riga, Working Paper 2/2003 - 22 S.

Thirlwall, A. (2001) Growth and Development, Athens: Papazissis Publications (in Greek).

\section{Figures and Tables}

Figure 1

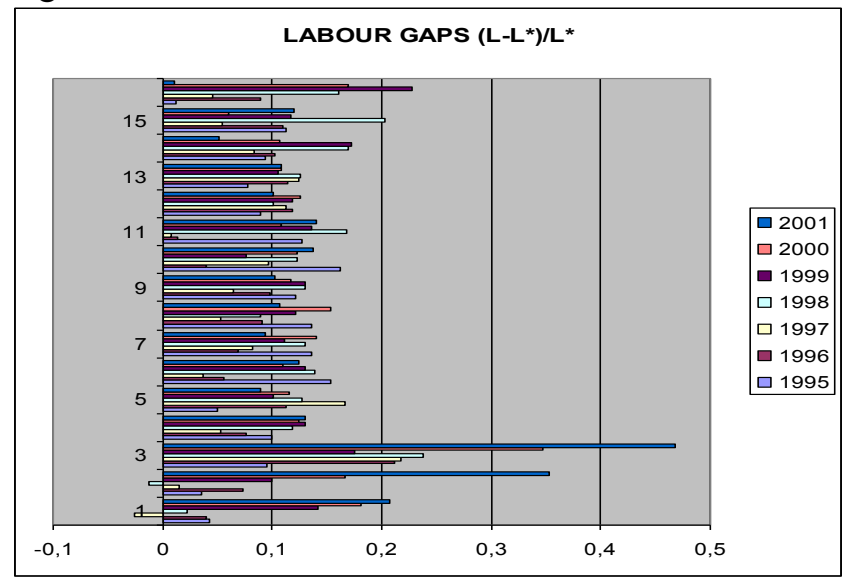

Figure 2

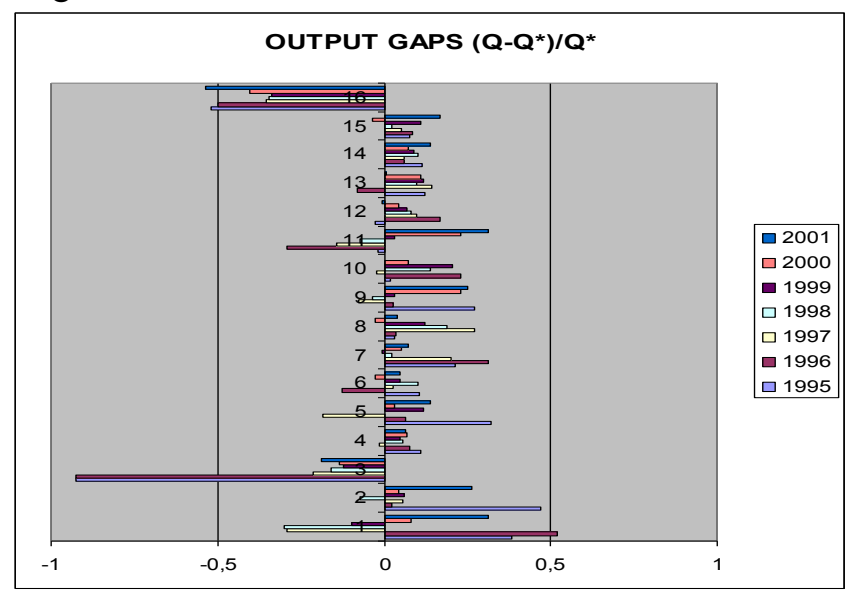

Figure 3

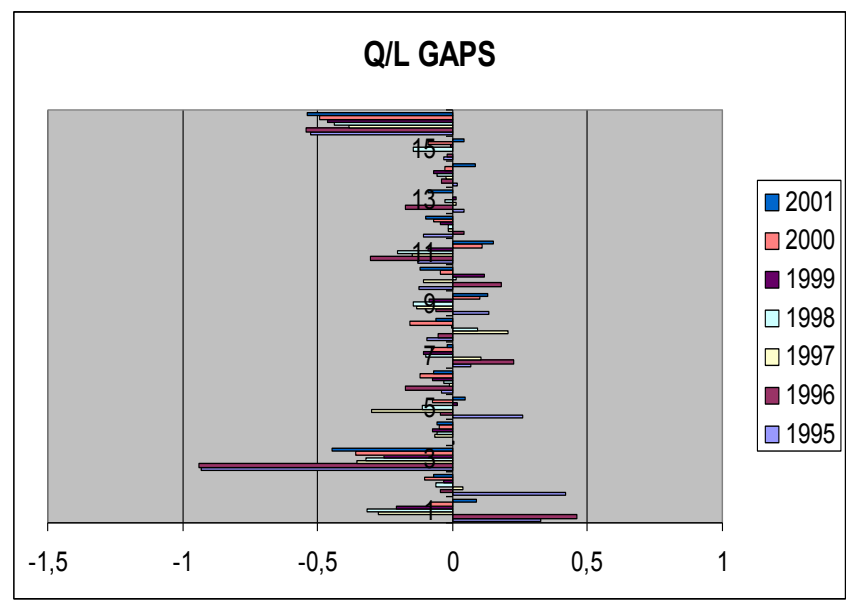


Table 1

\begin{tabular}{|c|l|}
\hline Sector & \multicolumn{1}{|c|}{ Description } \\
\hline 1 & Agriculture, Farming, Forestry \\
\hline 2 & Fishing \\
\hline 3 & Mining \\
\hline 4 & Manufacturing \\
\hline 5 & Electrical Energy, Natural Gas, Gas, Watering \\
\hline 6 & Construction \\
\hline 7 & $\begin{array}{l}\text { Retailing, Car, Motorcycles and Home Device } \\
\text { Repairing }\end{array}$ \\
\hline 8 & Hotels and Restaurants \\
\hline 9 & Transportation, Storage and Communication \\
\hline 10 & Finance and insurance \\
\hline 11 & Real estate and business services \\
\hline 12 & $\begin{array}{l}\text { National defense and public administration and } \\
\text { social security }\end{array}$ \\
\hline 13 & Education \\
\hline 14 & Health and Social Security \\
\hline 15 & Other Social and Personal Activities \\
\hline 16 & Private Households with Employed Persons \\
\hline & \\
\hline
\end{tabular}

Table 2

\begin{tabular}{|r|r|r|r|r|r|r|r|}
\hline & $\mathbf{1 9 9 5}$ & $\mathbf{1 9 9 6}$ & $\mathbf{1 9 9 7}$ & $\mathbf{1 9 9 8}$ & $\mathbf{1 9 9 9}$ & $\mathbf{2 0 0 0}$ & $\mathbf{2 0 0 1}$ \\
\hline $\mathbf{1}$ & 0.0421 & 0.0405 & -0.0254 & 0.0219 & 0,1423 & 0,1810 & 0,2077 \\
\hline $\mathbf{2}$ & 0.0349 & 0.0739 & 0.0156 & -0.0119 & 0,0994 & 0,1666 & 0,3529 \\
\hline $\mathbf{3}$ & 0.0946 & 0.2111 & 0.2171 & $0 ., 2375$ & 0,1751 & 0,3467 & 0,4679 \\
\hline $\mathbf{4}$ & 0.0998 & 0.0755 & 0.0530 & $0 ., 1189$ & 0,1300 & 0,1243 & 0,1307 \\
\hline $\mathbf{5}$ & 0.0500 & 0.1126 & 0.1664 & $0 ., 1276$ & 0,1011 & 0,1153 & 0,0890 \\
\hline $\mathbf{6}$ & 0,1540 & 0.0560 & 0.0365 & $0 ., 1391$ & 0,1305 & 0,1095 & 0,1242 \\
\hline $\mathbf{7}$ & 0.1355 & 0.0693 & 0.0827 & $0 ., 1308$ & 0,1109 & 0,1404 & 0,0932 \\
\hline $\mathbf{8}$ & 0.1358 & 0.0912 & 0.0523 & $0 ., 0895$ & 0,1216 & 0,1533 & 0,1067 \\
\hline $\mathbf{9}$ & 0.1207 & 0.0983 & 0.0648 & $0 ., 1307$ & 0,1307 & 0,1172 & 0,1031 \\
\hline $\mathbf{1 0}$ & 0.1615 & 0.0404 & 0.0970 & $0 ., 1227$ & 0,0769 & 0,1225 & 0,1370 \\
\hline $\mathbf{1 1}$ & 0.1267 & 0.0134 & 0.0082 & $0 ., 1678$ & 0,1361 & 0,1084 & 0,1399 \\
\hline $\mathbf{1 2}$ & 0.0887 & 0.1184 & 0.1125 & $0 ., 1004$ & 0,1178 & 0,1254 & 0,1013 \\
\hline $\mathbf{1 3}$ & 0.0770 & 0.1135 & 0.1248 & $0 ., 1263$ & 0,1051 & 0,1084 & 0,1082 \\
\hline $\mathbf{1 4}$ & 0.0933 & 0.1024 & 0.0839 & $0 ., 1690$ & 0,1730 & 0,1061 & 0,0514 \\
\hline $\mathbf{1 5}$ & 0.1120 & 0.1098 & 0.0539 & $0 ., 2027$ & 0,1175 & 0,0600 & 0,1195 \\
\hline $\mathbf{1 6}$ & 0.0124 & 0.0888 & 0.0459 & $0 ., 1604$ & 0,2276 & 0,1700 & 0,0106 \\
\hline
\end{tabular}

Table 3

\begin{tabular}{|r|r|r|r|r|r|r|r|}
\hline & $\mathbf{1 9 9 5}$ & $\mathbf{1 9 9 6}$ & $\mathbf{1 9 9 7}$ & $\mathbf{1 9 9 8}$ & $\mathbf{1 9 9 9}$ & $\mathbf{2 0 0 0}$ & $\mathbf{2 0 0 1}$ \\
\hline $\mathbf{1}$ & 0.3835 & 0.5200 & -0.2929 & -0.3017 & -0.0975 & 0.0807 & 0.3142 \\
\hline $\mathbf{2}$ & 0.4683 & 0.0232 & 0.0555 & -0.0731 & 0.0616 & 0.0441 & 0.2612 \\
\hline $\mathbf{3}$ & -0.9247 & -0.9260 & -0.2118 & -0.1613 & -0.1224 & -0.1357 & -0.1870 \\
\hline $\mathbf{4}$ & 0.1090 & 0.0761 & -0.0152 & 0.0555 & 0.0458 & 0.0690 & 0.0643 \\
\hline $\mathbf{5}$ & 0.3203 & 0.0646 & -0.1830 & 0.0004 & 0.1179 & 0.0299 & 0.1391 \\
\hline $\mathbf{6}$ & 0.1063 & -0.1281 & 0.0255 & 0.1018 & 0.0477 & -0.0275 & 0.0458 \\
\hline $\mathbf{7}$ & 0.2140 & 0.3118 & 0.2000 & 0.0212 & -0.0078 & 0.0500 & 0.0726 \\
\hline $\mathbf{8}$ & 0.0291 & 0.0338 & 0.2703 & 0.1903 & 0.1201 & -0.0282 & 0.0379 \\
\hline $\mathbf{9}$ & 0.2709 & 0.0271 & -0.0768 & -0.0349 & 0.0321 & 0.2311 & 0.2488 \\
\hline $\mathbf{1 0}$ & 0.0176 & 0.2293 & -0.0226 & 0.1399 & 0.2031 & 0.0712 & 0.0007 \\
\hline $\mathbf{1 1}$ & -0.0193 & -0.2930 & -0.1422 & -0.0722 & 0.0315 & 0.2316 & 0.3110 \\
\hline $\mathbf{1 2}$ & -0.0286 & 0.1673 & 0.0958 & 0.0813 & 0.0689 & 0.0433 & -0.0060 \\
\hline $\mathbf{1 3}$ & 0.1238 & -0.0800 & 0.1409 & 0.0973 & 0.1165 & 0.1112 & 0.0082 \\
\hline $\mathbf{1 4}$ & 0.1129 & 0.0587 & 0.0593 & 0.0999 & 0.0873 & 0.0737 & 0.1382 \\
\hline $\mathbf{1 5}$ & 0.0773 & 0.0849 & 0.0529 & 0.0242 & 0.1088 & -0.0348 & 0.1680 \\
\hline $\mathbf{1 6}$ & -0.5196 & -0.4994 & -0.3540 & -0.3439 & -0.3380 & -0.4036 & -0.5348 \\
\hline
\end{tabular}

Table 4

\begin{tabular}{|c|c|c|c|c|c|c|c|}
\hline & 1995 & 1996 & 1997 & 1998 & 1999 & 2000 & 2001 \\
\hline 1 & 0.3271 & 0.4618 & -0.2742 & -0.3175 & -0.2100 & -0.0829 & 0.08797 \\
\hline 2 & 0.4179 & -0.0472 & 0.0392 & -0.0623 & -0.0341 & -0.1041 & -0.0684 \\
\hline & -0.9317 & -0.9387 & -0.3526 & -0.3219 & -0.2539 & -0.3584 & -0.4462 \\
\hline & 0.0056 & 0 & -0.0648 & -0.0568 & -0.0744 & -0.0493 & -0.0582 \\
\hline 5 & 0.2581 & -0.0432 & -0.2989 & -0.1133 & 0.01562 & -0.0764 & 0.0461 \\
\hline & -0.0409 & -0.1739 & -0.0103 & -0.0323 & -0.0742 & -0.1222 & -0.0696 \\
\hline & 0.0695 & 0.2263 & 0.1073 & -0.0981 & -0.1070 & -0.0791 & -0.0193 \\
\hline & -0.0938 & -0.0531 & 0.2074 & 0.0921 & -0.0016 & -0.1570 & -0.0624 \\
\hline 9 & 0.1338 & -0.0638 & -0.1340 & -0.1457 & -0.0881 & 0.10292 & 0.1320 \\
\hline 10 & -0.1241 & 0.1816 & -0.1089 & 0.0153 & 0.1175 & -0.0450 & -0.1200 \\
\hline 11. & -0.1295 & -0.3024 & -0.1492 & -0.2053 & -0.0919 & 0.1115 & 0.1505 \\
\hline 12 & -0.1085 & 0.0429 & -0.0143 & -0.0168 & -0.0432 & -0.0722 & -0.0980 \\
\hline 13 & 0.0444 & -0.1747 & 0.0141 & -0.0264 & 0.0113 & 0.0015 & -0.0911 \\
\hline 14 & 0.0173 & -0.0403 & -0.0234 & -0.0592 & -0.0721 & -0.0296 & 0.0831 \\
\hline 15 & -0.0311 & -0.0215 & 0 & -0.1467 & -0.0069 & -0.0901 & 0.0431 \\
\hline 16 & -0.5241 & -0.5413 & -0.3826 & -0.4369 & -0.4627 & -0.4910 & -0.539 \\
\hline
\end{tabular}

